\title{
Justicia social, democracia y educación: la vigencia de viejos legados y desafíos presentes
}

\section{Social justice, democracy and education: old legacies validity and current challenges Justiça social, democracia e educação: a vigência de velhos legados e desafios presentes}

Juan Carlos Geneyro ${ }^{*}$

\section{Resumen}

El texto recupera planteos políticos y pedagógicos de principales autores de la modernidad respecto de las relaciones entre justicia social, democracia y educación, destacando la vigencia que mantienen en nuestra actualidad. Además de considerar a Comenio (1986) como un antecedente importante para uma educación básica común e igualitaria, en esa perspectiva analiza princípios pedagógicos de éste autor para luego abordar legados de Rousseau $(1988,2017)$ y Condorcet $(1997,2008)$ en dichas interrelaciones; así como el de Comte en cuanto al desarrollo de una religiosidad cívica y luego también algunos aportes de Durkheim (2003) en tales interrelaciones. A partir de reconocer la vigencia de estos legados, se plantean algunos nuevos desafíos que afronta la educación ennuestro tiempo respecto de la justicia social, la democracia y la educación.

Palabras claves: Democracia. Educación. Justicia social.

\section{Abstract}

This text rescues political and pedagogical issues of well-known and modern authors regarding the relationship between social justice, democracy and education, and highlights their validity in our days. Apart from considering Comenio (1986) as an important precedent for a basic, ordinary and equal education, this text analyzes - in the same line, his pedagogical principles in order to present Rousseau's $(1988,2017)$ and Condorcet's (1997, 2008) legacy in such interrelations, as well as Comte's legacy as regards the development of a civic religiousness, and Durkheim's (2003) insights about such interrelations. By recognizing the validity of these legacies, new challenges for current education in terms of social justice, democracy and education are proposed.

Keywords: Democracy. Education. Social justice.

Recebido em 07/03/2019 - Aprovado em 03/07/2019

http://dx.doi.org/10.5335/rep.v26i3.9445

Profesor y Licenciado en Ciencias de la Educación por la Universidad Nacional del Litoral, Argentina. Master en Educación por la Universidad de Puerto Rico, Puerto Rico. Doctor en Filosofía por la Universidad Autónoma de Barcelona, España. Profesor Consulto de la Universidad Nacional de Río Negro y de la Universidad Nacional de Lanús, Argentina. E-mail: juancarlosgeneyro@gmail.com 


\title{
Resumo
}

\begin{abstract}
O texto recupera projetos políticos e pedagógicos dos principais autores da modernidade a respeito das relações entre justiça social, democracia e educação, destacando a vigência que mantêm na atualidade. Além de considerar Comênio (1986) um antecedente importante para uma educação básica comum e igualitária, nesta perspectiva, analisam-se princípios pedagógicos do autor para, em seguida, abordar legados de Rousseau $(1988,2017)$ e Condorcet $(1997,2008)$ em tais interrelações; assim como o legado de Comte, quanto ao desenvolvimento de uma religiosidade cívica, além de alguns aportes de Durkheim (2003). Após reconhecer a vigência desses legados, colocam-se alguns novos desafios que afrontam a educação em nosso tempo a respeito da justiça social, da democracia e da educação.
\end{abstract}

Palavras-chave: Democracia. Educação. Justiça social.

Las cuestiones y preocupaciones relativas a la justicia social han recrudecido en los últimos tiempos, tal como lo señala la convocatoria temática para el número de esta revista. No obstante, hay que subrayar que las mismas son de larga data, más allá de que hoy en día los déficits en su realización adquieren particulares expresiones tanto en términos cuantitativos como cualitativos. Desde los inicios de la modernidad fueron configurándose legados sobre la necesidad de atender a la justicia social, tal como hoy la denominamos; vale decir a la necesidad de generar políticas y propuestas que favorecieran mejores condiciones de vida para quienes estaban privados de acceder a bienes básicos, necesarios e imprescindibles para constituirse como individuos y como ciudadanos. En suma, para tener una vida digna. En este artículo haré primero un repaso de algunos legados políticos y pedagógicos gestados en la Modernidad que, con distintos énfasis, fueron recuperados en las políticas y propuestas pedagógicas de varios países latinoamericanos a partir de sus procesos de independencia y luego también en la organización de los Estados Nacionales; particularmente en cuanto a la educación común y la formación de ciudadanía Luego, en una segunda parte, apuntaré algunos desafíos que se presentan en nuestra actualidad respecto de los mismos.

Una primera voz que antecede y se adelanta a los postulados modernos en cuanto a las relaciones y propuestas sobre la justicia social y la educación es la de Comenio, con una consigna principal que postula en su Didáctica Magna: enseñar todo a todos (1986). El principio de enseñar a todos, que retoman luego otros autores, concurre sin duda al postulado axiológico de la igualdad que es tan caro a la Revolución Francesa de fines del siglo XVIII y nutre también los procesos emancipatorios que se darán en nuestra América bajo el lema de Educar al Soberano; mientras que la consigna de enseñar todo fue luego recogida en la figura de la 
educación básica y obligatoria que instituyeron nuestros Estados Nacionales, sobre todo a partir de la segunda mitad del siglo XIX. Hay que recordar que Comenio también establece la graduación de la enseñanza y los niveles educativos; precisando caules contenidos y actividades debía abarcar necesariamente la enseñanza de ese "todo" en la escuela común. Otro precepto que se instalará en las propuestas pedagógicas posteriores y perdura hasta nuestros días es el de "instruir para las acciones de la vida". Puede destacarse también su propuesta de nueve reglas para "el arte de la enseñanza de las ciências" y es pionero en destacar la importancia de un principio didáctico, revolucionario para su época, de llevar la naturaleza al aula, así como valerse de láminas, pinturas y todo recurso que motive la percepción y conocimiento de los objetos a través de los sentidos (COMENIO, 1986, p. 202-204). Luego de editada su Didáctica en latín en 1640 publicará en 1658 el Orbis Sensus Pictus (el mundo sensible en imágenes), considerado como el primer método ilustrado de enseñanza. Vale la pena volver a releer sus escritos porque constituyen aportes importantes a la pedagogía y la didáctica; más allá de que en ellos - acorde con su época y sus creencias - Comenio otorgue una principal atención a la religión teológica.

Tiempo después esta concepción religiosa de Comenio será reconfigurada luego como religiosidad cívica, por la que abogarán distintos autores de la modernidad; entre ellos J. J. Rousseau, A. Comte, E. Durkheim. Sin duda que este es un principal legado que recogen varios de nuestros países en sus propuestas políticas y pedagógicas para la educación. ${ }^{1}$ Es innegable que el lema comeniano de enseñar todo a todos sigue teniendo plena vigencia en nuestros días, porque aún falta lograr su plena realización; al mismo tiempo que el desarrollo cultural, científico y tecnológico demanda que en nuestros respectivos países analicemos cuáles contenidos, actividades y recursos son los que debe comprender ese "todo", particularmente en lo que hoy llamamos Educación Básica. Uno de los primeros legados modernos que contribuye al acervo ético y político que conllevan las demandas y propuesta relativas a la justicia social, relacionadas con la democracia y la educación es el de Juan Jacobo Rousseau; particularmente si consideramos sus escritos del Discurso sobre el origen y fundamentos de la desigualdad entre los hombres, de El contrato social y de Consideraciones sobre el gobierno de Polonia. Es casi un lugar común referir a la inconformidad de Rousseau respecto a la sociedad de su época, así como su crítica a lo que consideraba como efectos perversos del desarrollo científico, que le valió enconados críticos, proscripciones de algunas de sus obras y también exilios. Puede apuntarse que se le han cuestionado ambivalencias conceptuales en 
algunos de sus planteamientos; entre otros, cómo concibe la libertad individual y el papel del Estado respecto a ella, como también en cuanto a la educación. ${ }^{2}$ Ello merecería un análisis particular; solo quiero aquí referirme a algunas de sus tesis que contribuyen a ese acervo político y pedagógico que conllevan las relaciones, de por sí complejas, entre justicia social, democracia y educación.

Sin duda, Rousseau es uno de los primeros autores de la modernidad que advirtió la necesidad de establecer condiciones de vida que pudieran establecer una realización equilibrada, armónica si se quiere, entre la libertad y la igualdad de todos los individuos, superando las desigualdades sociales que advertía en su época. ${ }^{3}$ En El contrato social (2017) se verifica esta preocupación, cuando establece algunos recaudos para la legitimidad y perdurabilidad del mismo. En el final de la primera parte del contrato (en algunas traducciones, Primer Libro) señala:

Bajo los malos gobiernos [la igualdad] no es más que aparente ilusoria; solo sirve para mantener al pobre en su miseria y al rico en su usurpación [de bienes]. En los hechos, las leyes siempre son útiles para los que poseen y perjudiciales para los que no tienen nada. De donde se sigue que el estado social es ventajoso para los hombres siempre cuando todos tengan algo y nadie tenga demasiado de nada (ROUSSEAU, 2017, p. 28).

Más adelante, en la misma obra, apunta precisiones sobre los caracteres y relaciones entre la libertad y la igualdad, introduciendo el papel del Estado en relación al cuidado y realización de una y otra, que vale transcribir:

Si se investiga en qué consiste precisamente el mayor bien para todos, que debe ser el fin de todo el sistema de legislación, se descubrirá que se reduce a estos dos objetos principales: la libertad y la igualdad. La libertad, porque toda dependencia particular es otro tanto de fuerza que se quita al cuerpo del Estado; la igualdad, porque la libertad no puede subsistir sin ella... con respecto a la igualdad, no hay que entender por esta palabra que los grados de poder y de riqueza sean absolutamente los mismos, sino que, en cuanto al poder, esté por debajo de toda violencia y que nunca se ejerza si no es en virtud del rango y de las leyes y que, en cuanto a la riqueza, ningún ciudadano sea tan opulento como para poder comprar a otro, y ninguno tan pobre como para estar obligado a venderse... Esta igualdad, dicen, es una quimera de la especulación que no puede existir en la práctica. Pero si el abuso es inevitable, ¿se sigue que no haya, por lo menos, que regularlo? Es precisamente porque las fuerzas de las cosas tiende siempre a destruir la igualdad que la fuerza de la legislación debe tender siempre a mantenerla (ROUSSEAU, 2017, p. 62-63, grifos nuestros).

Mucho después, Durkheim retomará esta línea de pensamiento en su tesis doctoral, La división del trabajo social. En este escrito apunta que las relaciones contractuales que emnarcan el trabajo obrero en la nueva sociedad industrial, aparentemente surgidas o devenida de relaciones paritarias no son tales, sino más bien injustas si se tiene en cuenta que una de las partes no depende de ese contrato para poder vivir y la otra necesariamente depende del mismo para poder subsistir. 
También hay que subrayar que Rousseau hizo particular énfasis en aquellas condiciones relativas a la educación que demandaban al Estado proveer medidas para propender a la justicia social, así como al papel de la educación y el magisterio en la configuración de una religiosidad civil y una ciudadanía reflexiva, comprometida y participativa en las cuestiones de interés público. Un siglo antes, ya Comenio había advertido la desigualdad en cuanto al acceso y disposición de escuelas para la educación básica y común (COMENIO, 1986, p. 83-84); cuestión que también observa Rousseau en la realidad de su entorno social en su ensayo sobre el Gobierno de Polonia:

No soy partidario de esa distinción entre colegios y academias que motiva una educación distinta y separada de la nobleza rica y de la pobreza pobre. Siendo todos constitucionalmente iguales, todos debe ser educados conjuntamente y de la misma manera, y si no puede establecerse una educación pública enteramente gratuita al menos será necesario ponerla a un precio asequible para los pobres (ROUSSEAU, 1988, p. 70).

Comenio había hecho hincapié que la desigualdad en cuanto al acceso a la escuela originaba no solo injusticia sino también perjuicio social, en tanto que niños de hogares carenciados con capacidades o excelentes ingenios estuvieran privados de la educación (COMENIO, 1986, p. 83-84). Por su parte Rousseau, con un ánimo humanista para el apunte de esas desigualdades, alertaba sobre los perjuicios para los propios niños, para el cuidado y "amor de sí mismo" y luego, también, en cuanto al ejercicio de la ciudadanía, así como para la realización de los valores que constituyen su ideario cívico. ${ }^{4}$ Es cierto que puede haber un cierto desencanto al leer el párrafo antes citado, cuando ingenuamente expone que con un precio más asequible también los pobres pueden acceder a una educación igualitaria de calidad. Pero si volvemos a las citas anteriores, podríamos concluir que también en él ya se encuentra una noción sobre el mandato para el Estado de concurrir a garantizar mediante leyes dicha educación, mandato que es recurrente en varios autores compatriotas suyos posteriores, como es el caso de Condorcet y el ya mencionado Durkheim.

Otro legado que considero trascendente para las políticas públicas en educación, también para la pedagogía y la didáctica, son los trabajos de M. J. Condorcet, que fuera considerado luego de su muerte, en 1794, como el último de los filósofos de la Ilustración francesa y el último de los enciclopedistas. En los inicios de la Revolución Francesa fue elegido Secretario de la Asamblea de 1791, y luego diputado. Con ese cargo, en nombre del Comité de Instrucción Pública, fue portavoz de un grupo de delegados 'girondinos' ante la Asamblea Legislativa para presentar en abril de 1792 el Informe general sobre la organización de la instrucción pública. En 
este Informe se encuentra una íntima relación entre la justicia social y la educación, en el que se la considera como una de sus principales expresiones, así como el mandato del poder político para garantizar el acceso a ella y reconocerla como vía indispensable para la formación y ejercicio de la ciudadanía:

Ofrecer a todos los individuos de la especie humana los medios de proveer a sus necesidades, de asegurar su bienestar, de conocer y ejercer sus derechos, de comprender y cumplir sus deberes. Asegurar a cada quien la facilidad de perfeccionar su industria, de hacerse capaz de cumplir las funciones sociales a las que tiene derecho de ser convocado, de desarrollar en toda su extensión los talentos que ha recibido de la naturaleza; y con ello, de establecer entre los ciudadanos una igualdad de hecho, y de convertir en realidad la igualdad política reconocida por la ley. Tal debe ser el primer fin de una instrucción nacional; y desde este punto de vista, ella es, para el poder público, un deber de justicia (CONDORCET, 1997, p. 251).

En este mismo Informe, además de los argumentos y propuestas para que sea el Estado quien asuma la responsabilidad de asegurar una educación básica, también destaca la advertencia de que es necesario proveer más educación a quienes están destinados a actividades laborales de escasa o nula necesidad de conocimientos, lo que probablemente puede originar - por desuso - el olvido de lo aprendido (CONDORCET, 1997, p. 253). Los efectos de tales situaciones luego fueron caracterizados en los análisis sociológicos de mediados del siglo XX como analfabetismo funcional.

Condorcet (2008) aborda de manera pormenorizada las principales características que debe acreditar la instrucción pública en cinco Memorias. En la primera de ellas, destaca que la sociedad debe al pueblo una instrucción pública, particularmente la instrucción común. En esta memoria realiza los primeros análisis y propuestas políticas, pedagógicas y didácticas para dicha instrucción común, que debe ser común para las mujeres y para los hombres, los que continuará en la siguientes Memorias apuntando también las características de los distintos grados de instrucción, así como las relativas a los maestros y otras profesiones. En una misma línea de pensamiento que Rousseau, argumenta que es necesario establecer más grados en la instrucción común para hacer a los ciudadanos capaces de cumplir funciones públicas. Este cometido de formación en ciudadanía es constitutivo del ideario que alienta la ampliación y la extensión de la educación pública y estatal en las políticas educativas de nuestros países hacia la segunda mitad del siglo XIX y principios del siglo XX. ${ }^{5}$ También, al igual que Comenio, destaca la necesidad de proveer una mayor educación en cantidad y complejidad cognitiva a quienes poseen talentos destacados que pueden contribuir con una formación especializada al progreso científico y al desarrollo social. Es interesante advertir que apunta principalmente 
a la responsabilidad de la sociedad, aunque generalmente se le ha atribuido al Estado - como mandatario social - dicha responsabilidad. Un tema al que otorga atención especial es al papel de la enseñanza de las lenguas y las ciencias para la socialización y la configuración de ciudadanía, que considera esenciales para la comunicación y la expresión de las propias ideas, como también para no depender de terceros en cuanto a los análisis, opiniones y posicionamientos personales ante los problemas comunes, así como para considerar las opiniones y propuestas legislativas de quienes ejercen roles políticos y gubernamentales (CONDORCET, 2008, p. 94-96; p. 128-129). Creo que importa destacar su preocupación por favorecer a través de la educación, el dominio y uso del lenguaje y la adquisición de los conocimientos científicos básicos para favorecer la autonomía y evitar la dependencia en cuanto a sus análisis y opiniones en los temas de interés público o común. Vale la pena leer o releer la propuesta de Instrucción Pública presentada por Condorcet ante la Asamblea de abril de 1792, así como las memorias de Condorcet, porque en esos escritos -aparte de los ya señalados- hay principios políticos y pedagógicos, así como consideraciones didácticas que aún hoy mantiene vigencia en diversas propuestas y prácticas educativas.

Antes, en un primer pié de página, hice referencia a la concepción de A. Comte sobre una moral cívica laica que se asienta en una religiosidad civil con valores tales como el altruismo, el amor al prójimo, la abnegación y el sacrificio en aras de afianzar el bien común. En buena medida son ejemplos de su observancia nuestros próceres, muchos de ellos incluso ofrendaron sus vidas para defender la patria. También apunté la reconversión de los símbolos y ritos de la religión teológica en una religiosidad civil, muchos de los cuales son considerados y practicados en las escuelas para afianzar la convivencia social y proveer una identidad nacional; cometido en el que es fundamental el papel del magisterio. Sin duda que esta concepción de la moral cívica es uno de los principales legados de Comte, además de sus principios metodológicos para el conocimiento científico y el papel de éste en las distintas disciplinas, que fueron decisivos para la elaboración de los propuestas curriculares de la educación básica y la secundaria en varios de nuestros países en la segunda mitad del siglo XIX. Cabe señalar que no abordó con especificidad el tema de las relaciones entre justicia social y educación, tampoco el tema de la democracia dado que en su Sistema de Política Positiva apunta que deben ser los científicos quienes gobiernen, ya que los políticos han perdido la confianza del pueblo en virtud de sus luchas y disputas egoístas para hacerse del poder material luego de la Revolución, descuidando la atención de un bienestar general. No obstante, influido 
por las tesis del llamado socialismo utópico, subyace en sus escritos la preocupación por alcanzar un estadio generalizado de bienestar común a todos los individuos, a través de un progreso sostenido de las ciencias y la aplicación de sus conocimientos en las actividades productivas (GENEYRO; PUIG; CASALI, 2016, p. 76-83). Por otra parte, cabe destacar que subrayó la importancia de lograr un "fondo común de verdades", con el fin de lograr identidad, convivencia y consenso social, condiciones para lograr dicho progreso y el bienestar general. ${ }^{6}$ Sin duda que varias de sus tesis, por ejemplo las relativas a la organización social y el papel o función de las distintas clases sociales, han merecido una multiplicidad de críticas. Vale la pena conocerlas, así como también la revalorización de partes de su obra que han hecho distintos autores en la actualidad. $\mathrm{Al}$ respecto, remito a una entrada sobre este autor, hecha en el Diccionario Iberoamericano de Filosofía de la Educación (GENEYRO, 2016a).

En 1905, en función de su contexto histórico, político y social, Durkheim expone un conjunto de argumentos para establecer la potestad del Estado para proveer una educación común, obligatoria, laica y gratuita a todos los niños y jóvenes de su país así como, a partir de ella, una educación heterogénea que brinde formación profesional acorde con los intereses y aptitudes de cada individuo. También sostiene como uno de los fines principales de ese proceso educativo de socialización sistemática el de constituir al individuo como una fuente autónoma de acción que apunta tanto a configurar ciudadanía activa y participativa en la democracia como a proveer formación especializada para el desempeño laboral (con base en una educación homogénea y, luego de ella, una heterogénea). En la línea del tema al que responde este artículo, en distintas partes de su obra cuestionó al economicismo clásico en su concepción de las funciones económicas como si fueran un fin en sí mismas y a la lógica del desarrollo del capitalismo industrial y los efectos o perjuicios sociales que originaba; en esta perspectiva, señala, apelando a un principio del utilitarismo, pese a no compartir muchas sus tesis y particularmente las relativas al papel del Estado:

[...] ¿de qué sirve acumular riquezas si no logran calmar los deseos del mayor número, si no que, al contrario, excitan sus impaciencias? Se olvida que las funciones económicas no son un fin en sí mismas, no son más que un medio para determinado fin, uno de los órganos de la vida social, y la vida social es, antes que nada, una comunidad armónica de esfuerzos [...] orientados hacia el mismo fin. La sociedad no tiene razón de ser si no brinda un poco de paz a los hombres, paz en sus corazones y paz en sus intercambios mutuos. Si la industria no puede ser productiva más que alterando esa paz y desencadenando la guerra, no vale la pena que cuesta. [...]. No sólo importa que muchas cosas sean producidas, sino que también lleguen regularmente y en cantidad suficiente a los trabajadores; que no se sucedan períodos de abundancia y períodos de carestía. Ahora bien, la ausencia de reglamentaciones impide esa regularidad (DURKHEIM, 2003, p. 78-79). 
Puede recordarse que los efectos perversos de ese desarrollo industrial de fines de siglo XIX fueron cuestionados también por el Papa León XIII, en su encíclica Rerum Novarum de 1891.

Hice antes referencia a la importancia que otorga Durkheim al valor de la autonomía; en el análisis que hace de la misma considera que su sentido y ejercicio está abierto y relacionado con las condiciones reales de existencia que tienen los individuos en su medio social; nuevamente aquí, como antes lo habían apuntado Rousseau y Condorcet en sus respectivos planteos, Durkheim entiende que le corresponde al Estado el mandato de concurrir a la ampliación de derechos y a atender a las condiciones de quienes están privados de una vida digna:

La persona forma parte del medio físico y social, al que está indisolublemente unida, por lo que no puede ser más que relativamente autónoma. Y, entonces cuál es el grado de autonomía que le conviene? La respuesta depende del estado de las sociedades [...]. Hubo un tiempo en que la servidumbre material (la esclavitud), contratada en ciertas condiciones no parecía en absoluto inmoral; la hemos abolido, pero ¿cuántas formas de servidumbre moral sobreviven? ¿Puede decirse que un hombre que no tiene de qué vivir es autónomo, que es dueño de sus actos? ¿Cuáles son, entonces, las dependencias legítimas y cuáles las ilegítimas? No puede darse una respuesta definitiva a estos problemas. Los derechos individuales están en evolución: progresan sin cesar y no es posible ponerles un límite que no deben superar. Lo que ayer no parecía ser más que un lujo, se convertirá mañana en un derecho. La tarea que incumbe al Estado es, entonces, ilimitada" (2003, p. 132, grifo nuestro).

Además de la importancia que tienen a mi juicio las categorías de dependencias legítimas y dependencias ilegítimas, que constituyen la apertura para los análisis que podemos hacer sobre nuestras propias realidades y distinguir unas y otras. Creo que todo el sentido de este último texto y estas categorías apuntadas puede orientar los interrogantes y el establecimiento de los indicadores (no solo cuantitativos) que hoy en día pueden informarnos acerca del estado de la justicia social en nuestros países.

Hago aquí una digresión: años atrás un filósofo italiano, Norberto Bobbio7, apuntó con perspicacia que una disyuntiva atraviesa la mayor parte de los escritos de filosofía política de la modernidad hasta nuestros días: ¿más iguales o más libres? También Axel Honneth, en su última obra editada en castellano, La idea del socialismo (2017), aborda las complejas y para él no resueltas interrelaciones que establece la principal consigna de la Revolución Francesa: "libertad, igualdad, fraternidad", las que considera como promesas no cumplidas de la Revolución. En este sentido, puedo decir que a mi juicio Durkheim es más demócrata que liberal; esto es, al igual que Rousseau, privilegia el valor de la igualdad como condición necesaria para el ejercicio de la libertad individual, entendiendo que dicha libertad 
supone y requiere el ejercicio igualitario de la misma por parte de sus conciudadanos. Esto es, supone una intersubjetividad que la instale como libertad social y la despoje del individualismo posesivo, que se gesta, entre otros, en el legado de algunas de las tesis de Hobbes, de B. Mandeville, de J. Locke y luego también en algunos de los escritos de J. S. Mill ${ }^{8}$. Para cerrar esta primera parte, puedo destacar que las tesis de Durkheim sobre el papel del Estado, el de la sociedad civil y sus organizaciones profesionales, así como sobre los perfiles éticos y procedimentales que esboza para alcanzar una efectiva democracia han sido recuperados en los últimos tiempos por distintos filósofos y científicos sociales, reconociéndolas como un legado principal para contribuir a una mejor realización de la democracia, tanto en Europa como en nuestra América (GENEYRO, 1991; GENEYRO et al., 2009; GENEYRO; PUIG; CASALI, 2016) .

Una reflexión recurrente hago cada vez que leo estos autores (otros también, por ejemplo John Dewey), a los que he referido para caracterizar legados que de una u otra manera ponen atención en los temas de la justicia social, la educación y la democracia, sin olvidar que el primero tratado, Comenio, no tiene un contexto socio-histórico donde la democracia esté instalada como una posibilidad de sistema político y vida social: en nuestras democracias actuales, a siglos de las tesis de Comenio, de Rousseau, de Condorcet; de más de un siglo para las tesis de Comte o de Sarmiento en cuanto a la Educación Popular, y también de Durkheim, persisten en nuestros países fuertes indicadores de injusticia social que desmerecen y obstaculizan la plena realización de los valores de la democracia. Este es indudablemente un principal desafío.

Mientras escribo este artículo, hoy, 29 de abril de 2019, el Observatorio de la Deuda Social Argentina, de la Pontifica Universidad Católica Argentina, ha dado a conocer su informe Pobreza, derechos e infancias en la Argentina: 2010-2018 (POY; TUÑ́́N, 2019). Los datos son, sin vueltas, una tragedia social: casi cinco millones de niños, niñas y adolescentes son "doblemente pobres". Los menores comprendidos en esta cifra viven en hogares que no alcanzan a cubrir la canasta básica de alimentos y, además, tienen vulnerados derechos findamentals en al menos una de las cinco dimensiones que considera el estudio: habitacional; acceso a la información; saneamiento; saludo; educación y alimentación. El estudio indica que la "pobreza multidimensional infantil" aumentó 4 puntos entre 2017 y 2018, período en el que 600.000 niños y jóvenes entre 0 y 17 años pasaron a engrosar la estadística de aquellos que están por debajo de la línea de pobreza por ingresos, pero además tienen déficit de alimentación, vivienda, salud, información o estimulación 
temprana/educación; revirtiendo la tendencia positiva de reducción de la misma que se estanca a partir de $2016 \mathrm{y}$, desde entonces no ha habido avances significativos en este indicador. A tenor de los datos económicos que hay para los primeros meses de este 2020, que no es dable esperar que mejoren significativamente a lo largo del año, no es aventurado señalar que estos índices de pobreza aumentarán todavía más. Queda a cargo de los lectores de otros países próximos indagar en los informes e indagaciones relativas a los déficits y deudas sociales que perviven a lo largo de los años por parte de quienes están carenciados o privados en una o más de las dimensiones apuntadas, que bien pueden ser indicadores básicos para ponderar el estado de la (in)justicia social en sus respectivas sociedades. He planteado en otros trabajos que fue tarea del Estado, y sigue siendo ahora tal como lo concibieron primeros autores de la filosofía política moderna tales como Hobbes y Locke, garantizar seguridad de vida y seguridad de bienes a sus gobernados; tarea que a juicio de esos autores lo arropaba de legitimidad ante los mismos. Con base en ese mandato, creo que es necesario ampliar su sentido originario y sostener que en la actualidad es el Estado quien debe de proveer aquellas condiciones que garanticen a todos los niños y jóvenes aquejados por las situaciones de pobreza material y simbólica una seguridad prospectiva. Porque, sin una vivienda digna, sin una buena alimentación, cuidados de salud, una educación de calidad y sin acceso a bienes esenciales, ¿qué futuro, que proyección de vida pueden tener esos niños y jóvenes como individuos y como ciudadanos? Este es, a mi juicio, un primer desafío principal e ineludible no solo para el Estado, sino también para la sociedad misma y sus instituciones, porque es en ella donde viven y se proyectan como tales.

En una de sus últimas obras publicadas, que titula Educación y Justicia Social en América Latina (2012), Juan Carlos Tedesco apunta una reseña de lo hecho en educación - especialmente en educación primaria y secundaria - desde fines del siglo XIX hasta fines del siglo XX, reconociendo tres modelos que orientaron las políticas y acciones educativas en nuestra región:

- El primero, cuya variable clave es la política y su categoría principal la de ciudadano, comprende desde los inicios de los Estados Nacionales en América Latina hasta la década de los años 60' del siglo pasado. En este modelo, apunta, la educación fue concebida como el proceso que haría posible homogeneizar culturalmente a la población y formar a las elites dirigentes.

- El segundo, cuyo primeros esbozos surgen hacia mediados del siglo XX y se afianza en los años 60's, concibe a la educación como la responsable de la formación de recursos humanos para el desarrollo económico y social. Aquí, 
la variable clave es la economía y una categoría principal es la de recursos humanos.

- Luego, le sucede el tercer modelo, gestado a principios de la década de los años 90 's, en un contexto de déficit de sentido de la educación, que originó exigencias de eficacia y eficiencia, asi como la aplicación de la lógica del mercado a la producción y distribución de un bien común como el conocimiento. Una variable que aparece con nuevos significantes es la de mercado, así como también categoría de cliente (TEDESCO, 2012).

Como lo señalo en un trabajo para un libro en homenaje a Juan Carlos Tedesco, fallecido en 2017, todo indica que algunos perfiles de los modelos reseñados se manifiestan a lo largo de los años hasta nuestra actualidad; al menos, para el caso argentino. Todavía mantiene vigencia el imaginario que asigna a la educación básica obligatoria (que hoy incluye la secundaria) el cometido de formar en ciudadanía junto con algunos intentos de proveer también alguna formación que capacite/habilite para el mercado laboral; propósito este último de muy poco alcance y logro, considerando la retracción de dicho mercado en virtud del cierre de pequeñas y medianas industrias, comercios y sectores de servicios, por obra y gracia de la preeminencia del accionar especulativo del capital financiero, que en mi país ha causado verdaderos estragos en los últimos años, con miles y miles de desempleados. Por otra parte, a lo largo de los años, el desarrollo científico y tecnológico y su aplicación en los distintos sectores de las actividades productivas y de servicios demandan más y mejores conocimientos y capacidades, que implican una ampliación de los trayectos educativos que posibilita dicha educación básica. Por lo menos, hasta mediados del siglo XX, hubo una mayor correspondencia/pertinencia entre la formación recibida en la educación primaria y secundaria; hoy la formación para el trabajo se ha desplazado en buena medida hacia la educación superior. Todo un desafío para replantear los sentidos y alcances de todos y cada uno de los niveles educativos.

Vale la pena apuntar aquí otro de los desafíos que hoy tenemos respecto a las interrelaciones entre justicia social, democracia y educación: la paulatina ampliación de los servicios educativos básicos que han favorecido el ingreso de niños y jóvenes de poblaciones carenciadas de bienes y servicios fundamentales para sus condiciones y proyectos de vida, ha estado acompañada por considerables índices de lo que en la jerga pedagógica se denomina fracaso o abandono escolar temprano (términos igual de antipático que el de deserción escolar). 
Podríamos acordar que hay un cierto velo ideológico - para decirlo en términos del Althusser - en el uso de esos términos porque, a la par que muestran hechos que pueden cuantificarse, ocultan causales que inciden para que ello suceda. Vaya una reflexión: más allá de las más conocidas y determinantes de índole económica y social, también inciden los abandonos y fracasos pedagógicos institucionales; generalmente éstos no son admitidos o considerados en aquellos imaginarios que endilgan a los propios alumnos o estudiantes dichos fracasos y abandonos. En verdad muchas veces ellos son los abandonados por el sistema, acompañado también por un desinterés social ${ }^{10}$ ¿Quién puede dudar que esta cuestión es un punto relevante de toda agenda que se plantee alcanzar una mayor justicia social? Justicia social que para su consecución requiere no solo una política programática sostenida por parte del Estado sino también una interpelación y acciones consecuentes a aquellos sectores que detentan un mayor dominio y poder decisorio sobre las condiciones que coadyuvan a las carencias y malestares endémicos de muchos individuos y grupos sociales en nuestras democracias. En su libro, Tedesco apunta la importancia de asegurar y proveer una educación de calidad para contribuir decididamente a la constitución de individuos autónomos, activos, dignos y solidarios:

[...] la educación forma para el mercado de trabajo, pero también para la ciudadanía y el desarrollo personal [...] si buscamos una sociedad con prosperidad para todos, la educación debe lograr que cada uno decida o elija si quiere ser plomero, chofer de taxi o ingeniero o abogado. Y una sociedad más justa y más igualitaria es aquella que ha logrado que todos estén en condiciones de elegir qué lugar quieren ocupar (TEDESCO, 2012, p. 115).

Tiempo atrás, uno de los principales desafíos educativos que afrontaron nuestros países desde sus procesos de independencia y luego de organización de sus Estados Nacionales fue Educar al Soberano que mereció políticas, leyes y acciones destinadas al desarrollo de la educación en sus distintos niveles y, lo que no es menor, erradicar el analfabetismo, considerado un valladar para quienes adolecían de los mínimos conocimientos para la lectura y la escritura, en desmedro de las condiciones habilitantes no solo para el ejercicio de la ciudadanía, sino también de sus posibilidades laborales. En buena medida, se la logrado el abatimiento de ese tipo de analfabetismo, pero subsisten otros posibles que constituyen nuevos desafíos, para lo cual Tedesco apunta dos líneas de acción educativa: la alfabetización científica y la alfabetización digital universal. Sin desmerecer la primera, que tradicionalmente ha sido atendida en los distintos planes de estudio y probablemente haya que revisar en sus supuestos, contenidos y finalidades, hoy en día adquiere una principal importancia dicha alfabetización digital. Esto es, el acceso, disposi- 
ción y uso informado de las tecnologías de la información y la comunicación. No solo es una de las dimensiones a atender por la justicia social (incluida como una de las variables para determinar niveles de pobreza en el estudio que mencioné anteriormente) si no que también tiene una íntima relación con el ejercicio de la individualidad y la ciudadanía en nuestras democracias.

En algunos trabajos he señalado que los nuevos lenguajes y recursos desarrollados por las tecnologías de la información y la comunicación, con múltiples incidencias en los procesos de producción de bienes y servicios, al igual que en las actividades de distintos ámbitos y organizaciones sociales, instalan nuevos desafíos pedagógicos y didácticos para la educación y sus instituciones. ${ }^{11}$ Para finalizar este artículo quiero hacer algunas otras consideraciones, más directamente relacionadas con el ejercicio de ciudadanía y la democracia. Nuestra historia indica que la educación fue concebida como una vía insoslayable para configurar ciudadanía y también para el desarrollo persona y social. Un lenguaje común y compartido fue considerado también un atributo para ejercer dicha ciudadanía y relacionarnos socialmente; así como para acceder al conocimiento y la información sobre las cuestiones e intereses públicos, favoreciendo la reflexión y el análisis sobre el acontecer político y social. Desde los procesos de independencia, la prensa escrita primero, luego también la radio, fueron instancias para difundir y compartir noticias, que alimentaron el ejercicio cívico individual y también el colectivo. No obstante, hay que advertir que algunos de esos medios de mayor edición y alcance, en el caso de Argentina por lo menos, desde fines del siglo XIX expresaron particulares intereses no solo políticos sino también económicos de determinados grupos dominantes del sector. En las últimas décadas se ha sumado la televisión como otro medio principal, de particular impacto por sus características y cobertura de audiencias; también aquí se advierten los sesgos ideológicos que permean buena parte de las noticias, análisis e informaciones de su programación. Tempranamente Dewey, hacia fines de la década de los años 20' en Estados Unidos, alertó sobre algunos efectos de la concentración de la propiedad de los medios masivos de comunicación y su accionar en la producción en masa de la opinión. Más recientemente, tanto Axel Honneth (2014) como Rainer Forst (2015, p. 136-138) han puesto la atención en cómo la televisión y la Internet pueden generar aparentes espacios e instancias de información, participación y reflexión, que conviene advertir y superar mediante aquellos espacios e instancias que impliquen el involucramiento directo con otros en relación a los problemas y necesidades próximas a su vida cotidiana. Al respecto, Honnet (2014, p. 405) apunta lo siguiente: 
[...] la ampliación y la eliminación de las fronteras del espacio público de la comunicación, posibilitadas digitalmente [podría generar] un espacio trasnacional de fronteras difuminadas, de construcción democrática de la opinión y la voluntad, cuyas consecuencias no tendrían beneficios para aquellos en el lugar donde están y en sus respectivas situaciones de necesidad. La libertad social de la autolegislación democrática se agrandaría para un grupo, el de la élites de orientación cosmopolita, pero para los otros, debido a la falta de acceso a los temas e informaciones relevantes, se reduciría.

\section{Consideraciones finales}

Las perspectivas y situaciones apuntadas nos indican la necesidad de reflexionar sobre las incidencias actuales de esos medios de comunicación, algunos de ellos muy orgánicos a particulares intereses, pero también las de los recursos y escenarios que abren otros medios tecnológicos de información y comunicación (internet, facebook, twuiters, blogs, páginas y revistas en soporte electrónico, etc.), así como preguntarnos sobre las disposiciones que deben favorecer los ámbitos y procesos educativos para saber leer y escribir, saber discernir, analizar y disponer de información, además de otros saberes tales como configurar y expresar ideas y opiniones, dialogar, argumentar, peticionar, etc., todos necesarios para nuestra vida personal y social que, tal como apuntan los legados expuestos, descansan en la adquisición y manejo del lenguaje común y de los propios de los conocimientos científicos y técnicos considerados indispensables en nuestros tiempos. Puedo, para terminar, apuntar una paradoja: el avance sostenido en cuanto a la disposición y uso que abren las nuevas tecnologías y dispositivos electrónicos, particularmente para niños y jóvenes incluso en circuitos y relaciones por fuera de los ámbitos educativos (aunque aún entre ellos dista de ser de un acceso generalizado), coexiste con una concepción de diseño de planes de estudios de talle único, desde un supuesto (podemos caracterizarlo de contrafáctico) de ingreso homogéneo, cuando la realidad indica cada vez más que es necesario atender a la diversidad y desigualdades sociales. Estos son algunos de los desafíos presentes y ellos son los que sostienen la vigencia de algunos viejos legados.

\section{Notas}

1 A. Comte propondrá una religión positiva, sustentada en el Gran Ser, que es el acervo de ejemplos de quienes en vida dieron muestra de asumir los valores postulados por la religión positiva. Es un precursor de una propuesta de moral cívica asentada en lo sacro laico, que será retomada por E. Durkheim tiempo después (GENEYRO; PUIG; CASALI, 2016, p. 76-90). Como he apuntado en otros trabajos, esta concepción de lo sacro laico supone un traspaso de símbolos y ritos, una reconversión, de la religión teológica a 
una religiosidad civil, que puede apreciarse en nuestras prácticas cívicas y educativas sobre todo a partir de la organización de los Estados Nacionales en nuestra América: del Dios Padre al Padre de la Patria; de la Biblia a la Constitución Nacional; del lábaro papal a la bandera nacional; de los salmos al himno y las cancjones patrias; del santoral y las misas, a la conmemoración de nuestros próceres y fechas patrias; del templo a la escuela; del sacerdocio al magisterio.

2 Solo a título de ejemplo: En El contrato social, la legitimidad de la coerción del Soberano sobre quien rehúse obedecer el mandato de la voluntad general, que forzará al individuo a "ser libre" acatándola...También, sus tesis del Emilio, donde se educa a éste por fuera de la jurisdicción del Estado y el papel decisivo que le otorga para impartir la educación en las Consideraciones sobre el Gobierno de Polonia.

3 Antes que Rousseau, tanto T. Hobbes como J. Locke, desde distintas premisas sobre la naturaleza humana y también sobre el Estado, habían abordado las condiciones que favorecieran una convivencia social que principalmente preservara la libertad, la seguridad de vida y de propiedad, con poca atención a aquellas condiciones que propendieran a una mayor igualdad en cuando a las condiciones materiales de vida y los derechos civiles y políticos entre los individuos integrantes/participantes del Estado Social. Pero en ellos, como lo he planeado en otros trabajos, No se encuentran mayores consideraciones sobre la justicia social, entendida como conjunto de condiciones que favorezcan una mayor equidad en cuanto al acceso y disposición de bienes básicos para una vida digna, autónoma y activa en términos culturales, políticos y económicos (GENEYRO; PUIG; CASALI, 2016; GENEYRO, 2018).

4 Puede consultarse sobre estos temas el excelente trabajo de Ousset (2005).

5 En nuestra América, a modo de ejemplo, D. F. Sarmiento, exiliado en Chile, escribe Educación Popular, obra editada en ese país en 1849. En dicha obra asienta: "[...] la última revolución en Europa (se refiere a la Francesa de 1789) dará por resultado final en la práctica, como ya ha dado en principio, el derecho de todos los hombres a ser reputados suficientemente inteligentes para la gestión de los negocios públicos por el ejercicio del derecho electoral, cometido para todos los hombres adultos de una sociedad, sin distinción de clase, condición o educación [...]. De este principio imprescriptible hoy nace la obligación de todo gobierno de proveer de educación a las generaciones venideras [...]. La condición social de los hombres depende muchas veces de circunstancias ajenas a la voluntad. Un padre pobre no puede ser responsable de la educación de sus hijos; pero la sociedad tiene interés vital en asegurarse que todos los individuos que han de venir con el tiempo a formar la Nación se hayan, por la educación recibida en su infancia, preparado suficientemente para desempeñar las funciones sociales a que serán llamados. El poder, la riqueza y la fuerza de una nación dependen de la capacidad industrial, moral e intelectual de los individuos que la componen, y la educación pública no debe tener otro fin que el aumentar estas fuerzas de producción, de acción y de dirección, aumentando cada vez más el número de individuos que la posean" (SARMIENTO, 2011, p. 48).

${ }^{6}$ Como bien se sabe, la influencia de los adherentes al positivimo comteano fue muy significativa en varios de los países latinoamericanos a partir de la segunda mitad del siglo XIX; un ejemplo de ello es el lema de Ordem e Progresso que porta la bandera nacional de Brasil. Por su parte Juárez en México, en los años 60' del siglo XIX, utilizó la ley de los tres estadios (teológico, metafísico, positivo) para analizar el pasado y presente de su país, en la llamada Oración Cívica de Guanajato.

7 Disponible en: https://www.nexos.com.mx/?p=4808. Acceso en: 14/8/2019.

8 Un análisis sobre la concepción de John Stuart Mill sobre este tema puede encontrarse en Geneyro, Puig y Casali (2016, p. 75-111).

9 Uno de ellos es Axel Honneth, quien recupera tanto a Durkheim como a Dewey en dos de sus más recientes obras editadas en español (2014; 2017).

${ }^{10}$ Aunque merece un desarrollo particular, con base en un término de uso frecuente en pedagogía y didáctica, el de trayectoria educativa, ceo que deberíamos instalar estaciones de servicio en distintos tramos y etapas del recorrido, que le permitieran a cada alumno o estudiante $\square$ según sus necessidades $\square$ encontrar apoyos o asistencias para poder proseguir su recorrido y alcanzar la meta.

${ }^{11}$ Veáse Geneyro (2018). 


\section{Referencias}

COMENIO, J. A. Didáctica Magna. España: Akal, 1986.

CONDORCET, M. de. Bosquejo de un cuadro histórico de los progresos del espíritu humano y otros textos. México: Fondo de Cultura Económica, 1997.

CONDORCET, M. de. Cinco memorias sobre la instrucción pública. Argentina: Ediciones del Signo, 2008.

DURKHEIM, E. Lecciones de Sociología: Física de las costumbres y del Derecho y otros escritos sobre el individualismo, los intelectuales y la democracia. Buenos Aires/Madrid: Miño y Dávila Editores, 2003.

FORST, R. Justificación y crítica. Perspectivas de una teoría crítica de la política. Buenos Aires: Katz, 2015.

GENEYRO, J. C. La democracia inquieta: E. Durkheim y J. Dewey. Barcelona: Antrhopos, 1991.

GENEYRO, J. C. A. Comte. In: SALMERON, A. et al. (coord.). Diccionario Iberoamericano de Filosofía de la Educación. México: FCE/UNAM, 2016a. Disponible en: http://www.fondodeculturaeconomica.com/dife/definicion.aspx?l=C\&id=39. Acceso en: 14/8/2019.

GENEYRO, J. C. J. S. Mill. In: SALMERON, A. et al. (coord.). Diccionario Iberoamericano de Filosofía de la Educación. México: FCE/UNAM, 2016b. Disponible en: http://www.fondodeculturaeconomica.com/dife/definicion.aspx?l=C\&id=39. Acceso en: 14/8/2019.

GENEYRO, J. C. E. Durkheim. In: SALMERON, A. et al. (coord.). Diccionario Iberoamericano de Filosofía de la Educación. México: FCE/UNAM, 2016c. Disponible en: http://www.fondodeculturaeconomica.com/dife/definicion.aspx?l=D\&id=52\&w=durkheim. Acceso en: 14/8/2019.

GENEYRO, J. C. Filosofía, formación docente y educación para la ciudadanía. In: CENCI, A. V.; DALBOSCO, C. A.; MÜHL, E. H. Sobre filosofía e educação: racionalidade, amizade e formação docente. Passo Fundo: UPF Editora, 2018. p. 294-313. E-book. Disponible en: http://editora.upf.br/images/ebook/sobre_filosofia_e_educacao_final.pdf. Acceso en: 14/8/2019.

GENEYRO, J.; PUIG, R.; CASALI, C. Filosofía de la Educación. Bernal: Universidad Nacional de Quilmes, 2016.

GENEYRO, J. et al. ¿Por qué leer Durkheim hoy? México: Fontamara, 2009.

GENEYRO, J. et al. ¿Por qué leer a Mill hoy? México: Fontamara, 2013.

HONNETH, A. El derecho a la libertad: Esbozo de una eticidad democrática. Madrid: Katz, 2014.

HONNETH, A. La idea del socialismo. Una tentativa de actualización. Madrid: Katz, 2017.

OUSSET, A. R. Presencia de J. J. Rousseau en el pensamiento educativo del liberalismo mexicano: Los valores éticos en la formación del ciudadano. Córdoba: Ed. Universitas/FFyH (Universidad Nacional de Córdoba), 2005. 
POY, S.; TUÑóN, I. Pobreza, derechos e infancias en la Argentina: 2010-2018 [en línea]. Barómetro de la Deuda Social de la Infancia. EDSA Serie Agenda para la Equidad 2017-2025. Boletín no 1. Observatorio de la Deuda Social Argentina. Universidad Católica Argentina, 2019. Disponible en: http://bibliotecadigital.uca.edu.ar/greenstone/cgi-bin/library.cgi?a=d\&c=investig acion\&d=pobreza-derechos-infancias-argentina-2019. Acceso en: 14/8/2019.

ROUSSEAU, J. J. Consideraciones sobre el gobierno de Polonia y su proyecto de reforma. Madrid: Tecnos, 1988.

ROUSSEAU, J. J. El contrato social. Buenos Aires: Colihue, 2017.

SARMIENTO, D. F. Educación Popular. Buenos Aires: UNIPE, 2011.

TEDESCO, J. C. Educación y Justicia Social en América Latina. Madrid: Siglo XXI, 2012. 